Advances in Geosciences, 6, 95-101, 2006

SRef-ID: 1680-7359/adgeo/2006-6-95

European Geosciences Union

(c) 2006 Author(s). This work is licensed

under a Creative Commons License.

\title{
El Niño Southern Oscillation (ENSO) and global warming
}

\author{
B. Nyenzi and P. F. Lefale \\ World Climate Programme (WCP), World Meteorological Organization (WMO), Genevé, Switzerland \\ Received: 9 May 2005 - Revised: 17 October 2005 - Accepted: 18 October 2005 - Published: 9 January 2006
}

\begin{abstract}
It is widely accepted by the international scientific community that human activities have increased atmospheric concentrations ${ }^{1}$ of greenhouse gases (GHG) and aerosols since the pre-industrial era. This increase has contributed to most of the warming $\left(0.6 \pm 0.2^{\circ} \mathrm{C}\right)$ observed over the 20th century, land areas warming more than the oceans, with the 1990s very likely to be the warmest decade of the 20th century (IPCC, 2001). How this warming influences the occurrence, severity and frequency of ENSO episodes remains highly uncertain. The IPCC (2001) assessment of the scientific literature found insufficient evidence to suggest any direct attribution between increase in ENSO events that occurred in the last 20 to 30 years of the 20th century and global warming (IPCC, 2001). However, assessments carried out since then (e.g. IPCC Fourth Assessment Report (AR4), in preparations) suggest El Niño events have become more frequent, persistent and intense during the last 20 to 30 years compared to the previous 100 years. Attribution to global warming, however, remains highly uncertain. Efforts to simulate and model past, present and future behaviour of ENSO under a warming world due to enhanced GHG concentrations produce conflicting results. Since substantial internally-generated variability of ENSO behaviour on multi-decadal to century timescales occurs in long, unforced atmospheric-oceanic general circulation model (AOGCM) simulations, the attribution of past and future changes in ENSO amplitude and frequency to external forcing like GHG concentrations cannot be made with certainty. Such attribution would require extensive use of ensemble climate experi-
\end{abstract}

Correspondence to: B. Nyenzi

(BNyenzi@wmo.int)

${ }^{1}$ Observed changes in atmospheric concentration of the major GHG over the $20^{\text {th }}$ century are given in Table SPM- 1 of the IPCC report, Climate Change 2001; Synthesis Report, Contribution of Working Groups I, II, and III to the Third Assessment Report of the Intergovernmental Panel on Climate Change (p. 5). For example, atmospheric concentration of $\mathrm{CO}_{2}$ over the 20th century was $280 \mathrm{ppm}$ for the period 1000-1750 rising to $368 \mathrm{ppm}$ by 2000 . Present levels (2005) are estimated at close to $370 \mathrm{ppm}$. ments or long experiments with stabilised GHG forcing. Although there are now better ENSO simulations in AOGCM, further model improvements are needed to simulate a more realistic Pacific climatology and seasonal cycle of the key modes influencing the climate of the region, as well as more realistic ENSO variability. More research is needed to further enhance scientific understanding of possible teleconnections between ENSO and global warming. It is worth noting the IPCC AR4 due to be release in September 2007, would provide a more detailed assessment of ENSO and global warming than what is being covered in this paper.

\section{Introduction}

Scientific understanding and public awareness of climate change $^{2}$ have both advanced notably in recent years. This has led to numerous policy responses at the local, national, regional and international level. The entry into force of the Kyoto Protocol in February 2005 has further placed climate change at the forefront of international policy making. These policy developments have led to increasing demands for up to date policy-relevant scientific advice on the likely effects of global warming on some of the key components of the climate system, in particular, those components that are poorly understood and are yet to be fully assessed. One of those is the El Niño Southern Oscillation (ENSO) ${ }^{3}$.

\footnotetext{
${ }^{2}$ Climate change usage in this paper refers to any change in climate over time, whether due to natural variability or as a result of human activity (IPCC definition). This usage differs from that in the United Nations Framework Convention on Climate Change (UNFCCC), where climate change refers to a change of climate that is attributed directly or indirectly to human activity that alters the composition of the global atmosphere and that is in addition to natural climate variability observed over comparable time periods.

${ }^{3}$ ENSO is the largest mode of interannual variability of the global climate system, with a peak in the power spectra around the 2-8 year frequency band. It is accompanied with a teleconnection pattern that extends out of the Pacific region. Global warming could
} 




Fig. 1. Simplified principal feedback loops active in El NiñoSouthern Oscillation (ENSO). The fast loop (right) gives rise to instability responsible for the development of an El Niño, the slow loop (left) tends to dampen and reverse the anomalies, so that together, these processes excite oscillations (Source: IPCC, 2001).

This paper assesses the latest scientific literature on ENSO and global warming. It attempts to answer some of the key questions relating to ENSO and global warming such as whether there is a relationship between ENSO and global warming, are we likely to see more intense and frequent ENSO episodes under a warming world and how well the current Atmospheric Oceanic Global Climate Models (AOGCM) simulate and predict past, present but more importantly future ENSO episodes. It is predominantly based on the work of the IPCC, in particular, its report "Climate Change 2001: the Scientific Basis. Contribution of Working Group I to the Third Assessment of the Intergovernmental Panel on Climate Change" 4 as well as some more recent papers in the scientific literature (e.g., UCAR, 1997; Trenberth, 1999; Herbert et al., 2002, Alves et al., 2004; Guilyardi et al., 2004).

\section{El Niño Southern Oscillation (ENSO)}

ENSO is the largest mode of interannual variability of the global climate system, with a peak in the power spectra

influence ENSO episodes' occurrence, severity and frequency. The connection, however, is highly tenuous and uncertain.

${ }^{4}$ The IPCC (2001) WGI Third Assessment Report (TAR) is the most comprehensive scientific assessment of past, present and future climate change. It analysis an enormous body of observations of all components of the climate system, catalogues increasing concentrations of atmospheric greenhouse gases, assesses present scientific understanding of the processes and feedbacks which govern the climate system, projects scenarios of future climate change using a wide range of models for future emissions of GHG and aerosols and makes a detailed study of whether human influence on climate can be detected. See other IPCC reports (e.g. Climate Change 2001, Synthesis Report (2001)) and other scientific publications (e.g. Climatic Change) for detailed assessment of ENSO and global warming. around the 2-8 year frequency band (IPCC, 2001). It is accompanied with a teleconnection pattern that extends out of the Pacific region (e.g. see, Timmermann et al., 1999; Changnon, 1999; Stern et al., 1999; IPCC, 2001 for detailed assessments of the impacts of the 1997-1998 El Niño event globally and nationally).

ENSO is generated by ocean-atmosphere interactions internal to the tropical Pacific and overlying atmosphere (IPCC, 2001; WMO, 2003; NOAA, 2005). Positive temperature anomalies in the eastern equatorial Pacific (characteristic of an El Niño event) reduce the normally large sea surface temperatures (SSTs) difference across the tropical Pacific. As a consequence, the trade winds weaken, the Southern Oscillation Index (SOI), defined as the sea level pressure difference between Tahiti and Darwin, becomes anomalously negative, and sea level falls in the west and rises in the east by as much as $25 \mathrm{~cm}$ as warm waters extend eastward along the equator.

At the same time, these weakened trades typically reduce the upwelling of cold water in the eastern equatorial Pacific, thereby strengthening the initial positive temperature anomaly. The weakened trades also cause negative offequatorial thermocline depth anomalies in the central and western Pacific. These anomalies propagate westward to Indonesia, where they are reflected and propagate eastward along the equator. Thus some time after their generation, these negative anomalies cause the temperature anomaly in the east to decrease and change sign. The combination of the tropical air-sea instability and the delayed negative feedback due to sub-surface ocean dynamics can give rise to atmospheric oscillations. Two of these feedbacks are schematically illustrated in Fig. 1.

Attempts to define ENSO remain elusive. International efforts, for example, mainly through the work of the World Climate Programme (WCP) of WMO and the Commission for Climatology $(\mathrm{CCl})$ to reach an agreed operational definition for ENSO remains out of reach. To date no internationally agreed operational definition of ENSO (WMO Update, 2005). However, the member countries of the WMO Regional Association (RA) IV recently adopted ENSO indices and definitions (NOAA, 2005). WMO RA IV defines El Niño and La Niña as follows:

El Niño: A phenomenon in the equatorial Pacific Ocean characterized by a positive sea surface temperature (SST) departure from normal (for the 1971-2000 base period) in the Niño 3.4 region greater than or equal in magnitude to 0.5 degrees Celsius, averaged over three consecutive months.

La Niña: A phenomenon in the equatorial Pacific Ocean characterized by a negative sea surface temperature (SST) departure from normal (for the 1971-2000 base period) in the Niño 3.4 region greater than or equal in magnitude to 0.5 degrees Celsius, averaged over three consecutive months.

The above definitions, adopted by US NOAA since September 2003, are widely being use in the operational forecasting and climate research communities to date. These definitions are also use in the case of climate change research purposes relating to ENSO and global warming. 


\section{Observed global climate variability and change}

Climate variability and change over the 20th century have been detected in the observational records. In its assessment of the scientific literature, the IPCC (2001) concluded "an increasing body of observations gives a collective picture of a warming world and other changes in the climate system" and that "most of the observed warming over the last 50 years is attributable to human activities." The IPCC (2001) found that over both the last 140 years and 100 years, the best estimates are that global average surface temperature have increased by approximately $0.6^{\circ} \mathrm{C}$ since the late 19 th century, with $95 \%$ confidence limits of close to 0.4 to $0.8^{\circ} \mathrm{C}$ (Fig. 2a). Moreover, the rate and duration of warming of the 20th century was found to be much greater than in any of the previous nine centuries (Fig. 2b). Similarly, it is likely ${ }^{5}$ that the 1990s have been the warmest decade and 1998 the warmest year of the millennium (IPCC, 2001).

Most of this increase occurred in two periods, from about 1910 to 1945 and since 1976. Spatially, the largest and more recent warming was in the wider extra tropical Northern Hemisphere. The warming rate during the period 1976 to $2000\left(0.17^{\circ} \mathrm{C} /\right.$ decade $)$ was considered slightly larger than the rate of warming during the 1910 to 1945 period $\left(0.14^{\circ} \mathrm{C} /\right.$ decade $)$, although the total increase in the Earth's surface temperature was larger for the 1910 to 1945 period (IPCC, 2001). The IPCC (2001) also noted that there was a faster rate of warming over land compared with the oceans in the 1990s. The high global temperature associated with the 1997-1998 El Niño event stood out in both land surface and tropospheric temperatures as an extreme event, even after consideration of the recent rate of warming ${ }^{6}$. In the case of the oceans, the IPCC (2001) analysis showed that the global ocean heat content has increased since the late 1950s. More than half the heating was contained in the uppermost $300 \mathrm{~m}$ where it is equivalent to an average temperature increase of $0.037^{\circ} \mathrm{C} /$ decade. $^{7}$ This increase is superimposed on substantial global decadal variability.

With regards to ENSO, the IPCC (2001) found the interannual variability of ENSO has fluctuated substantially over the 20th century, with noticeably reduced variability during the period 1920 to 1960, compared with adjacent periods (Figs. 3 and 4).

The IPCC (2001) also found the frequency and intensity of ENSO had increased from the mid-1979s to 2000 compared with the previous 100 years. Warm phase ENSO episodes have been relatively more frequent, persistent, or intense than

\footnotetext{
${ }^{5}$ In the IPCC (2001) TAR WG I Summary for Policy Makers and in the Technical Summary, the following words have been used where appropriate to indicate judgmental estimates of the confidence abut the statements: virtually certain (greater than 99\% chance that a result is true); very likely (90-99\% chance); medium likelihood (33-66\% chance); unlikely (10-33\% chance); very unlikely (1-10\% chance); exceptionally unlikely (less than $1 \%$ chance).

${ }^{6}$ Ibid.

${ }^{7}$ Ibid.
}
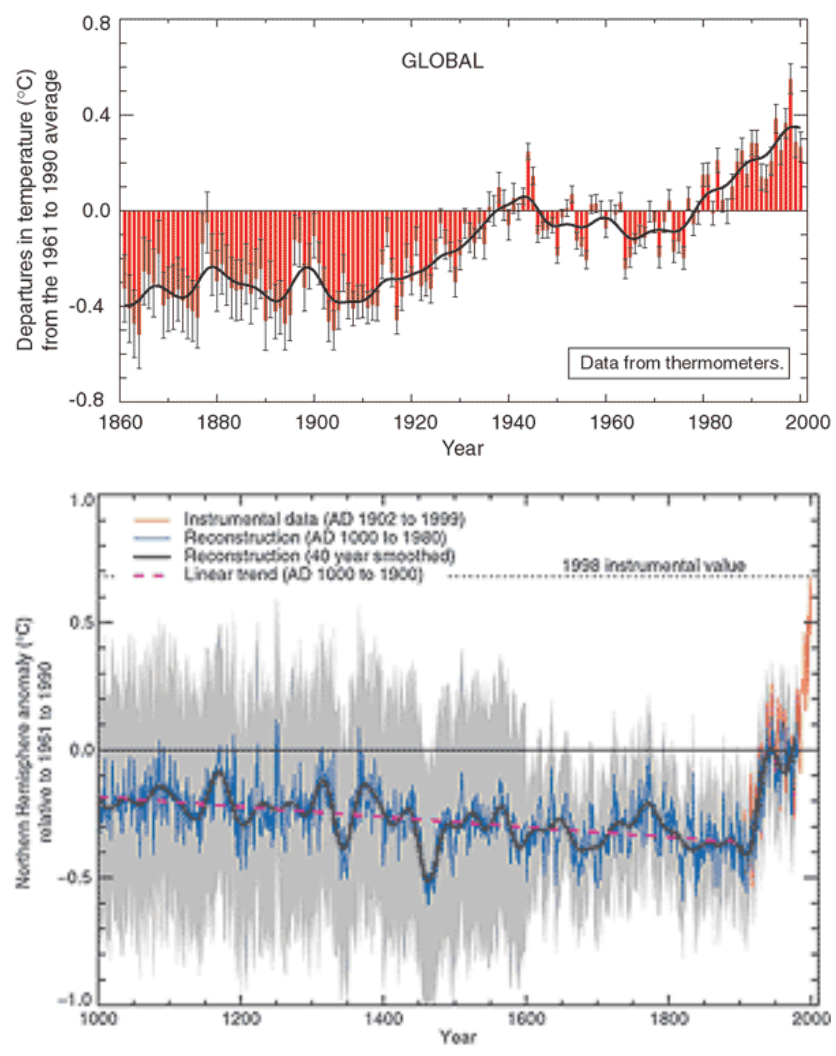

Fig. 2. Variations of the Earth's surface temperature over land from 1860 to 2000 over the last millennium. (a) The Earth's surface temperature is shown year by year (red bars) and approximately decade by decade (black line, a filtered annual curve suppressing fluctuations below near decadal time-scales). (b) The year-by-year reconstruction (blue curve) and 50 year average (black curve based on the reconstructed curve) variations of the average surface temperature of the Northern Hemisphere for the past 1000 years have been reconstructed from 'proxy' data calibrated against thermometer data. The grey region represents the $95 \%$ confidence range in the annual data. These uncertainties increase in more distant times and are always much larger than in the instrumental record due to the use of relatively sparse proxy data. Nevertheless the rate and duration of warming of the 20th century has been greater than in any previous nine centuries (Source: IPCC, 2001).

the opposite cold phase episodes since the mid-1970s. This recent behaviour has been attributed more to variations in precipitation and temperature over much of the global tropics and subtropics and some mid-latitude areas than to enhanced GHG concentrations. However, the IPCC (2001) concluded the overall effect of this change was likely to have made a small contribution to the increase in global surface temperature during the last decades of the 20th century.

\section{Characterisation of ENSO changes under a warming world - What changes could lay ahead?}

In its efforts to characterise ENSO changes under enhanced GHG concentrations, the IPCC (2001) examined whether the 


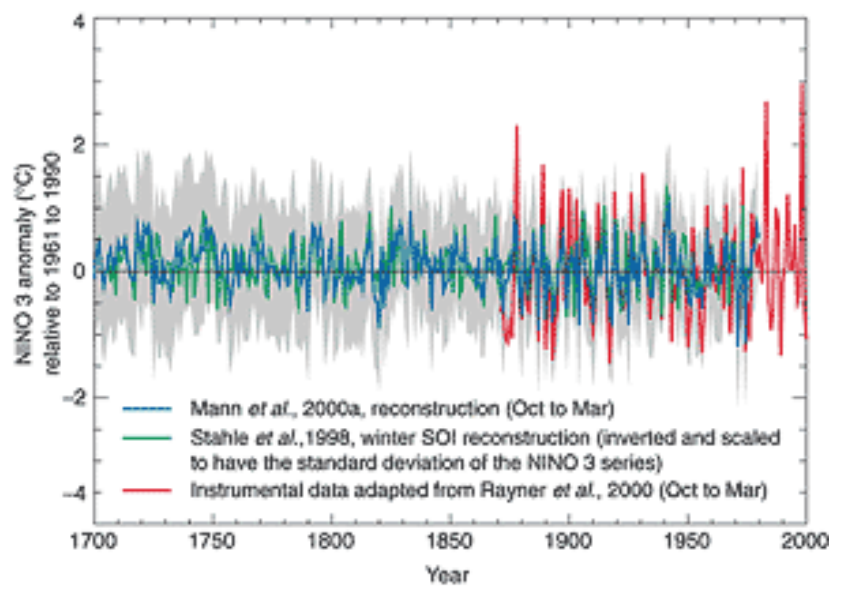

Fig. 3. Reconstructions since 1700 of proxy-based ENSO indices. Shown are the Northern Hemisphere cold-season (Oct-Mar) mean NINO 3 index of Mann et al. (2000a) and the Northern Hemisphere winter SOI index of Stahle et al. (1998). The SOI series is scaled to have the same standard deviation as the NINO 3 index, and is reversed in sign to be positively correlated with the NINO 3 series. An instrumental NINO 3 index from 1871 to 2000 is shown for comparison (Rayner et al., 2000; see also Fig. 4), with two standard error limits (grey shaded) of the proxy NINO 3 reconstruction (Source: IPCC, 2001).

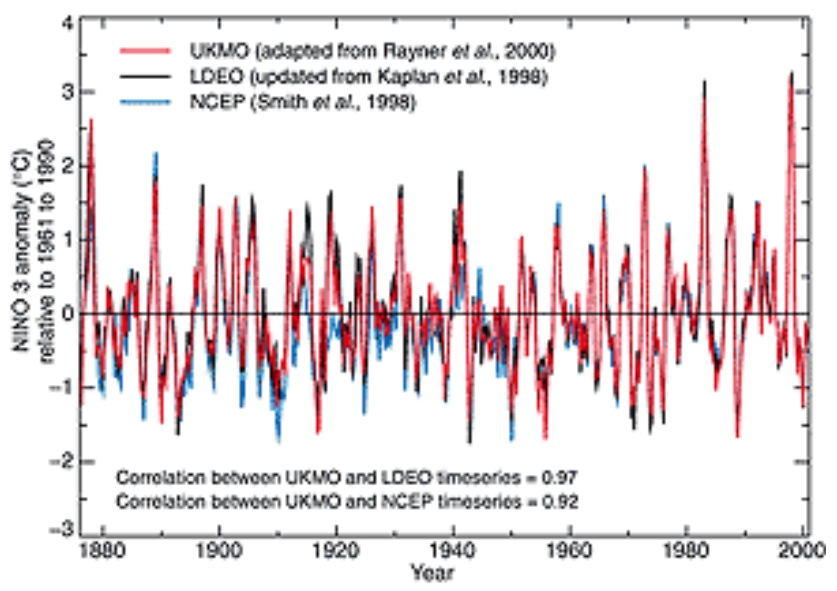

Fig. 4. El Niño-La Niña variations from 1876 to 2000 measured by sea surface temperature in the region $5^{\circ} \mathrm{N}$ to $5^{\circ} \mathrm{S}, 150$ to $90^{\circ} \mathrm{W}$. Reconstructions using pattern analysis methods from (a) red: UK Met Office (UKMO) Hadley Centre sea ice and sea surface temperature data set version 1 (Rayner et al., 2000); (b) black: from the LamontDoherty Earth Observatory (LDEO) (Kaplan et al., 1998); (c) blue: the National Centers for Environmental Prediction (NCEP) analysis (Smith et al., 1998). 1876 is close to the earliest date for which reasonably reliable reconstructions can be made (Source: IPCC, 2001).

long-term warming of the Pacific sea surface temperatures (SSTs) would shift toward a more El Niño- or La Niña-like regime.

Analyses of several AOGCM outputs suggested that as global temperatures increased due to enhanced GHG concentrations, the Pacific climate would tend to resemble a more
El Niño-like state (IPCC, 2001). The reasons for such a response vary considerably, depending on the model representation of cloud feedback, the quality of the unperturbed El Niño state in the models or the stronger evaporative damping of the warming in the warm pool region, relative to the eastern Pacific due to non-linear Clausius-Clapeyron relationship between the temperature and saturation mixing ratios (IPCC, 2001).

Other models suggested a different ENSO response to enhanced GHG concentrations (e.g. Noda et al. (1999b) as cited by the IPCC, 2001). This study demonstrated a La Niña-like response under a warming world. Other models (e.g. Cai and Whetton, 2000) reproduced an initial La Niña like pattern, which then becomes an El Niño like pattern due to subducted warm extra-tropical water that penetrates through the subtropics into the tropics in their model (IPCC, 2001). Moreover, Cane et al. (1997) reproduce a La Niña-like response when they use a simple coupled model study where the dominant role of ocean dynamics in the heat balance over the tropical Pacific was used for a specified uniform positive forcing across the Pacific basin (IPCC, 2001). These conflicting results suggest that current AOGCM are yet to be fully developed to be able to successfully model ENSO in response to sustained long term warming of Pacific SSTs. Assessment of whether El Niño variability (the amplitude and/or the frequency of temperature swings in the equatorial Pacific) would increase or decrease under enhanced GHG concentrations was also carried out by the IPCC (2001). They found the outputs from the AOGCM again produced conflicting results, varying from slight decreases or little change in amplitude to a small increase in amplitude (Figs. 5a and b).

The IPCC (2001) also examined the impact of ENSO on the weather and climate of the Pacific basin, the key region for ENSO onsets, and how patterns would change in response to global warming. It was concluded future seasonal precipitation extremes associated with a given ENSO event are likely to be more intense due to the warmer, more El Niñolike mean base state projected in the models. ${ }^{8}$ This could lead to the tropical Pacific and Indian Ocean regions anomalously wet areas becoming wetter and anomalously dry areas becoming drier during future ENSO events. ${ }^{9}$

Some studies (e.g. Collins 2000b) suggested early models with poor skill in reproducing present day ENSO found little or no changes in ENSO with increased GHG concentrations, while those models with more realistic simulation of present day ENSO (e.g. see Timmermann et al., 1999) found an increase in the occurrence of cold events. Collins (2000a) similarly found an increase in the amplitude and frequency of ENSO in simulation of the UK Hadley Centre Model (HadCM2). The performance of models in reproducing the ENSO phenomenon has improved enormously over the last ten years (Guilyardi et al., 2004), particularly in the atmospheric component and the application of observations in initializing forecasts (Alves et al., 2004).

\footnotetext{
${ }^{8}$ Ibid.

${ }^{9}$ Ibid.
} 
Most present day models reproduce an ENSO like variability, although very few models correctly simulate the mean state or the seasonal cycle and the interannual variability in tropical regions (e.g. Guiyardi et al., 2003). However, further enhancements of the models continue. Delworth et al. (2000), for example, reported that the simulated ENSO in the GFDL model is characterised by a spatial structure with larger amplitude in the central Pacific than observed, deficient amplitude in the eastern equatorial Pacific, and a time scale that is too long. These deficiencies may be related to the coarse resolution of the model.

Taking all these into consideration, one concludes the response of ENSO to increase GHG concentrations show markedly different results with different generations and features of the models. There are still other key atmospheric and ocean dynamics that are yet to be incorporated in the models if they are to simulate ENSO more fully.

In summary, the conflicting results from the models suggest that there appears to be little support to the idea of major changes of ENSO intensity or frequency as a consequence of enhanced GHG concentrations. However, the IPCC (2001) cautious that El Niño-like patterns could occur over a variety of time-scales ${ }^{10}$, ranging from inter-annual to interdecadal, either without any change in natural forcing or as a response to external forcing such as increased $\mathrm{CO}_{2}$ concentrations. These uncertainties make it difficult to reach any concrete conclusions about changes in future ENSO events. Since substantial internally-generated variability of ENSO statistics on multidecadal to century timescales occurs in long unforced atmospheric oceanic general circulation model (AOGCM) simulations, attribution of past and future changes in ENSO amplitude and frequency to external forcing by enhanced greenhouse gases cannot be made with certainty. Such attribution would require extensive use of ensemble climate experiments or long experiments with stabilised GHG forcing. More research is needed to further enhance our scientific understanding of present and future behaviour of ENSO under global warming.

\section{The role of the World Climate Programme of WMO in advancing our understanding of ENSO and global warming}

The WMO's World Climate Programme (WCP) ${ }^{11}$ was established in 1980 with the goal of fostering global understanding of the Earth's complex climate system, its manifestations and changes over time through such activities as climate system monitoring and climate change detection, as well as improvements to prediction and applications of climate information (WMO, 2005). The WCP is made up of four key components, the World Climate Data and Monitoring Programme,

\footnotetext{
${ }^{10}$ The same is true for current efforts to assess and predict ENSO events. See discussion on the current ENSO at the latest WMO El Niño Update (April 2005) at www.wmo.int

${ }^{11}$ Visit WMO web site www.wmo.int for further information on the work of the WCP.
}

(a) ECHAM4/OPYC

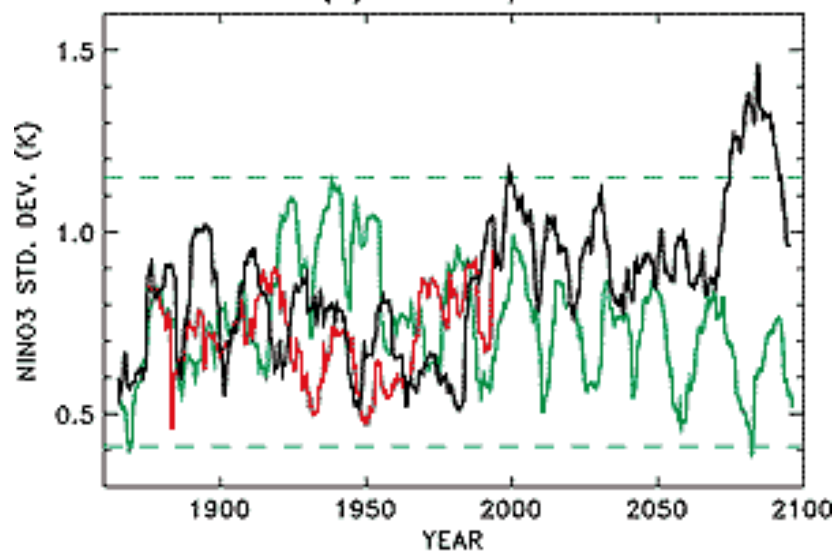

(b) $\mathrm{HadCM} 3$

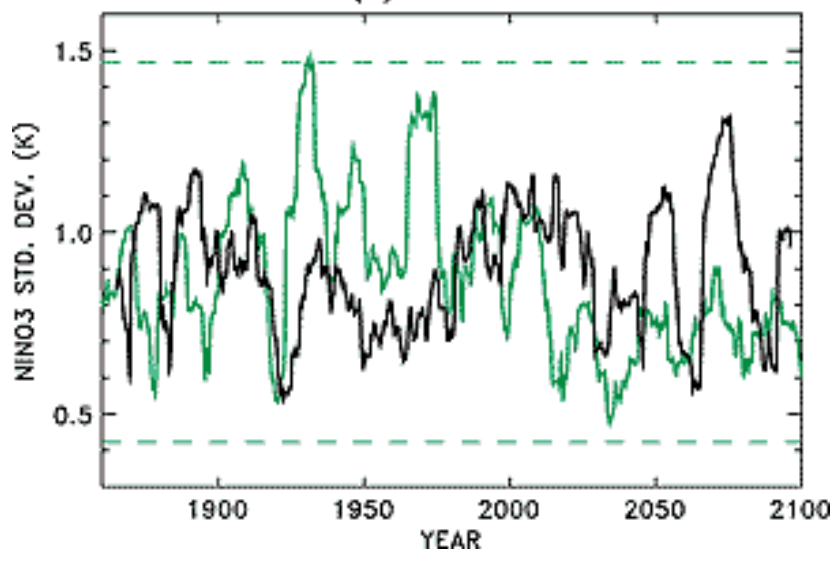

Fig. 5. Standard deviations of Niño-3 SST anomalies (Unit: ${ }^{\circ} \mathrm{C}$ ) as a function of time during transient greenhouse warming simulations (black line) from 1860 to 2100 and for the same period of the control run (green line). Minimum and maximum standard deviations derived from the control run are denoted by the dashed green lines. A low-pass filter in the form of a sliding window of 10 years width was used to compute the standard deviations. (a) ECHAM4/OPYC model. Also shown is the time evolution of the standard deviation of the observed SST anomalies from 1860 to 1990 (red line). Both the simulated and observed SST anomalies exhibit trends towards stronger interannual variability, with pronounced inter-decadal variability superimposed, (reproduced from Timmermann et al., 1999), (b) HadCM3 (Collins, 2000b) (Source: IPCC, 2001).

the World Climate Applications and Services Programme, which are both the responsibility of the WMO's WCP, the World Climate Impact Assessment and Response Strategies Programme (managed by UNEP), and the World Climate Research Programme, overseeing initially by WMO and International Council of Sciences (ICSU) and later in 1993 also by the Intergovernmental Oceanographic Commission (IOC) of the United Nations Education Scientific and Cultural Organization (UNCESCO) - see Fig. 6.

Since its establishment, the WCP has helped advance scientific understanding of the major components of and processes influencing the climate system, including ENSO. After the 1982-1983 El Niño event, the international scientific 


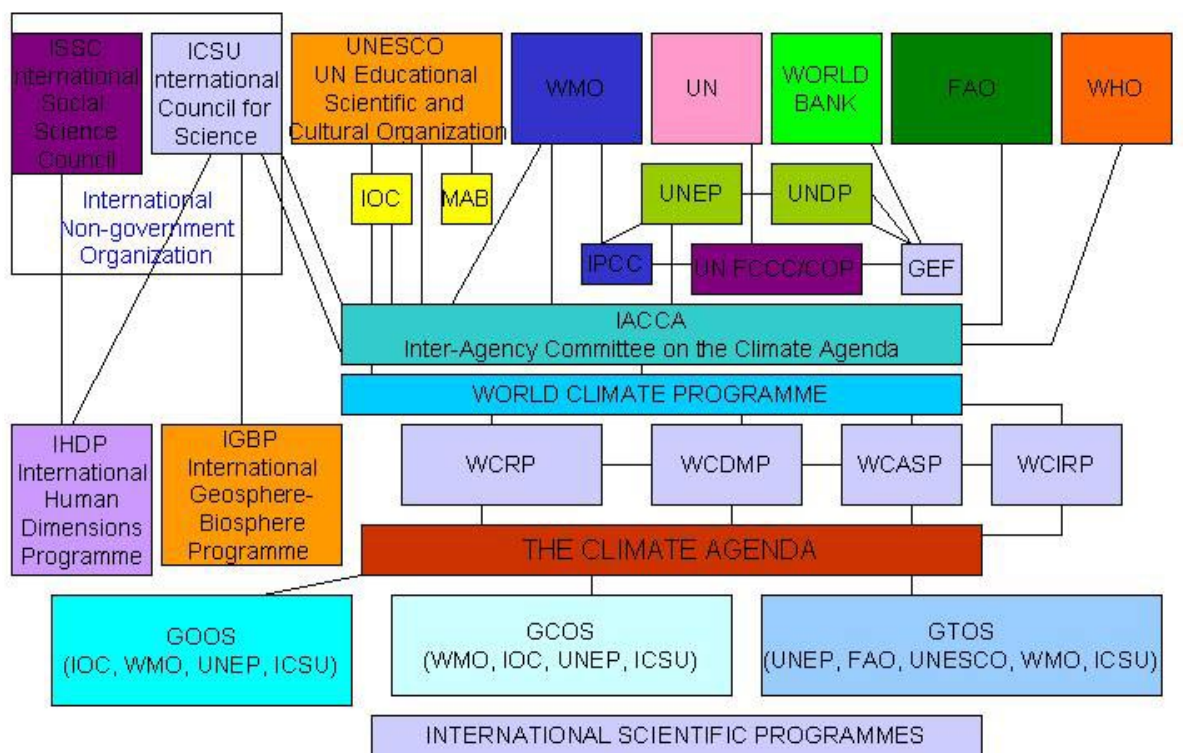

Fig. 6. International Climate Programmes and Activities. The World Climate Programme is a major component of the Climate Agenda.

community launched the Tropical Ocean Global Atmospheric and Climate Observing Research (TOGA/CORE) which greatly assisted in further improving understanding of ENSO. WMO, through its WCP, in collaboration with other international programmes such as the World Climate Research Programme (WCRP), Group on Earth Observations (GEO), the Global Climate Observing System (GCOS) and the IPCC, will continue to provide assistance to the international community in further monitoring and understanding ENSO and global warming.

\section{Summary of findings and conclusions}

The scientific literature to date suggests that global warming due to emissions of GHG from human activity is occurring. However, the where, when and how (rate of change), this warming would impact on the climate system and society remain highly uncertain. In terms of the connection between ENSO and global warming, the scientific literature provides insufficient evidence to date to suggest any direct link between the recent observed increase in ENSO episodes and global warming. Some studies (e.g. those cited by the IPCC AR4, in preparations) carried out since the release of the IPCC TAR in 2001, suggest El Niño events have become more frequent, persistent and intense during the last 20 to 30 years compared to previous 100 years. However, these recent studies also reaffirm the key findings from the IPCC TAR, in that attempts to model past, present and future behaviour of ENSO under a warming world continued to produce conflicting results, based in part on the characteristics of the models themselves.

Since substantial internally-generated variability of ENSO behaviours on multi-decadal to century timescales occurs in long, unforced atmospheric oceanic general circulation model AOGCM simulations, it is very difficult to attribute past and future changes in ENSO amplitude and frequency to external forcing like GHG concentrations. Such attribution would require extensive use of ensemble climate experiments or long experiments with stabilised GHG forcing.

Although ENSO simulations in AOGCM have improved in recent years, further model enhancements are required to stimulate a more realistic Pacific climatology and seasonal cycle as well as more realistic ENSO variability. It is likely increased in ocean resolution, atmospheric physics and possibly flux correction would have an important effect on the response of the ENSO in the models. Improvements in these areas will be necessary to gain further confidence in future ENSO behaviour under a warming world.

We conclude there is insufficient evidence to date to suggest any changes in the intensity or frequency of ENSO as a consequence of global warming. More research is needed to further enhance scientific understanding of the teleconnections between ENSO and global warming.

Acknowledgements. We would like to thank the IPCC Secretariat, in particular, J. Fernandes Skaalvik, UNEP/GRID-Arendal, Longum Park, Norway, for providing the IPCC TAR figures. We also are grateful to L. Malone and P. Hechler, staff of the WMO World Climate Programme, for their invaluable comments and suggestions to improve the paper. The views express herewith are solely of the authors and do not represent views of WMO or the IPCC. Any mistakes are the full responsibility of the authors.

Edited by: P. Fabian and J. L. Santos

Reviewed by: two anonymous referees 


\section{References}

Alves, O., Balmaseda, M. A., Anderson, D., and Stockdale, T.: Sensitivity of dynamical seasonal forecast to ocean initial conditions, Quart. J. Roy. Meteor. Soc., 130, 647-667, 2004.

Cane, M. A., Clements, A. C., Kaplan, A., Kushnir, Y., Pozdnyakov, D., Seager, R., Zebiak, S. E., and Murtugudde, R.: Twentieth century sea surface temperature trends, Science, 275, 957-960, 1997.

Cai, W. and Whetton, P.: Evidence for a time-varying pattern of greenhouse warming in the Pacific Ocean, Geophys. Res. Lett., 27, 2538-2550, 2000.

Changnon, S. A.: Impacts of the 1997-98 El Niño - Generated Weather in the United States, Bulletin of the American Meteorological Society, 80 (9), 1819-1827, 1999.

Collins, M.: The El Niño Southern Oscillation in the second Hadley Centre coupled model and its response to greenhouse warming, J. Clim., 13, 1299-2000, 2000a.

Collins, M.: Understanding uncertainties in the response of ENSO to greenhouse warming, Geophys. Res. Lett., 27, 3509-3512, 2000b.

Delworth, T. L., Stouffer, R. J., Dixon, K. W., Spelman, M. J., Knutson, T. R., Broccoli, A. J., Kusher, P. J., and Wetherald, R. T.: Review of simulations of climate variability and change with the GFDL R30 coupled climate model, Clim. Dyn., 19, 555-574, 2002.

Guilyardi, E., Delecluse, P., and Cassano, J. J.: Evaluation of Polar MM5 simulations of Antarctica atmospheric circulation, Mon. Wea. Rev., 131, 384-411, 2003.

Guilyardi, E., Gualdi, S., Slingo, J. M., Navarra, A., Delecluse, P., Cole, J., Madec, G., Roberts, M., Latif, M., and Terray, L.: Representing El Niño in coupled ocean-atmopshere GCMS; the dominant role of the atmospheric component, J. Clim., in press, 2004.

Herbert, J. M. and Dixon, R. W.: Is ENSO Phenomenon Changing as a Result of Global Warming?, Phys. Geogr., 23 (3), 196-211, 2002, available at: http://www.ingentaconnect.com/content/bell/ pgeo/2002/00000023/00000003/art00002, last access: 22 March 2005.

IPCC: Climate Change 2001: The Scientific Basis, in: Contribution of Working Group I to the Third Assessment Report of the Intergovernmental Panel on Climate Change, edited by: Houghton, J. T., Ding, Y., Griggs, D. J., Noguer, M., van de Linden, P. J., Dai, X., Mashell, K., and Johnson, C. A., Cambridge University Press, Cambridge, UK and New York, USA, 1-16, 105-164, 503-504, 567-568, 2001a.

IPCC: Climate Change 2001: Synthesis Report, in: Contribution of Working Groups I, II, and III to the Third Assessment Report of the Intergovernmental Panel on Climate Change, edited by: Watson, R. T., Albritton, D. L., Barker, T., Bashmakov, I. A., Canciani, O., Christ, R., Cubasch, U., Davidson, O., Gitay, H., Griggs, D., Halsnaes, K., Houghton, J., House, J., Kindzewicz, Z., Lal, M., Leary, N., Magadza, C., McCathy, J. J., Mitchell, J. F. B., Moreira, J. R., Munasinghe, M., Noble, I., Pachauri, R., Pittock, B., Prather, M., Riches, R. G., Robinson, J. B., Sathaye, J., Schneider, S., Scholes, R., Stocker, T., Sundararaman, N., Swart, R., Taniguchi, T., and Zhou, D., Cambridge University Press, Cambridge, UK and New York, USA, 397 pp., 2001 b.
Mestas-Nuez, A. M. and Enfield, D. B.: Potential Climatic induced changes in the Gulf of Mexico, available at: http://www. usglobec.org/reports/rep19/rep19.abs.mestas-nunez.html, last access: 22 March 2005 at 5.34 pm Geneva local time, 2000.

Noda, A., Yukimoto, S., Yamaguchi, K., and Yamaki, S.: Relationship between natural variability and $\mathrm{CO} 2$-induced warming pattern: MTI AOGCM Experiment, 10h Symposium on Global Change Studies, 10-15 January 1999, Dallas, Texas, American Meteorological Society, Boston, Mass., pp. 359-362, 1999.

Stern, P. C. and Easterling, W. E. (Eds.): Making Climate Forecast Matter, National Academy Press, Washington, D.C., USA, 7-10, 1999.

Timmermann, A., Oberhuber, J., Bacher, A., Esch, M., Latif, M., and Roeckner, E.: Increased El Niño/Southern Oscillation like in a model forced by future greenhouse warming, Nature, 298, 694-696, 1999.

Trenberth, K. E.: The Extreme Weather Events of 1997 and 1998, Consequences, 5 (1), 3-15, 1999, available at: www.earthscape. org/p2/cqs/v5n199/v5n199_03.html, last access: 22 March 2005.

UCAR: ENSO and Global warming: What's the connection? available at: http://www.ucar.edu/communications/quarterly/ winter97/connection.html, last access: 22 March 2005 at 5.34 pm Geneva time, 1997.

US NOAA: World Meteorological Organization Region IV Adopts Consensus El Niño and La Niña Index and Definitions, Press release, April 28, 2005, available at: http://usinfo.state.gov/ xarchives/display.html?p=washfile-english $\{\backslash \&\} \mathrm{y}=2005\{\backslash \&\}$ $\mathrm{m}=$ April $\{\backslash \&\} \mathrm{x}=20050428121122$ lcnirellep0.8599665 $\backslash \backslash \&\} \mathrm{t}=$ livefeeds/wf-latest.html, last access: 1 May 2005 at $1.45 \mathrm{pm}$ Geneva time, 2005.

WMO: World Climate News, No. 26., January, 2005, World Meteorological Organization (WMO), Geneva, Switzerland, pp. 3-4, 2005.

WMO: El Niño Update, 16 April 2005, World Meteorological Organization, Geneva, Switzerland, 2005, available at: http://www. wmo.int, last access: 20 April 2005.

WMO: Climate Into the 21st Century, edited by: Burroughs, W., Cambridge University Press, The Edinburgh Building, Cambridge CB2 2 RU, UK, New York, NY 10011-4211, USA, VIC 3207, Australia, 28014 Madrid, Spain, Cape Town 8001, South Africa, 72-73, 2003. 